\title{
Research on Influencing of New Generation Employee's Future Work Self Salience on Work Engagement
}

\author{
Zi-long Cui* \\ Management School, Chongqing Technology and Business \\ University \\ Chongqing, China \\ ziaiai@126.com
}

\author{
Li-xin Chen \\ Management School, Chongqing Technology and Business \\ University \\ Chongqing, China \\ chen li xin@163.com
}

\begin{abstract}
Drawing upon self-determination perspective, the current study examined the relations of future work self salience, work engagement, occupational self-efficiency and person -vocation fit. Result from 475 new generation employee's valid data showed that future work self salience positively correlated with work engagement, and this relations was mediated by occupational self-efficiency. Implications of these findings and future directions are discussed.
\end{abstract}

Keywords-Future work self salience; Occupational self-efficiency; Person-vocation fit; Engagement

\section{INTRODUCTION}

New generation employees (born after 1980) have gradually become the important subject of enterprise staffs. Their creative ability and professional skills were critical success factors in enterprise competition. With the impact of less structured and more boundaryless careers, new generation employees in workplace tends to have obscure career goals and self-concept which lead to low engagement and high turnover intention. According to the Meister (2010), Employers will face a huge challenge: to recruit, develop and motivate employees of all ages and backgrounds amid breakneck change. So organization should provide an intensely personalized social environment to attract new generation employees [1]. The work values discrepancy between generations posed challenges for organizations. In the last two decades, workplace engagement has emerged as a focal topic in the organization literature [2]. Previous study has demonstrated that job character factors served as an important predictor for work engagement based on social exchange theory and self-determination theory. However, the role personal factors such as self-concept, a crucial construct is not clear in engagement influence mechanism. To address this concern, we draw upon identity-based perspective to investigate the role of occupational self-efficiency on the effect future work self salience on work engagement. As shown in Fig.1, the present research had two goals. The first goal was to identity future work self salience that may contribute to work engagement. The second goal was to test the mediation mechanism of occupational self-efficiency.

\footnotetext{
* Corresponding author
}

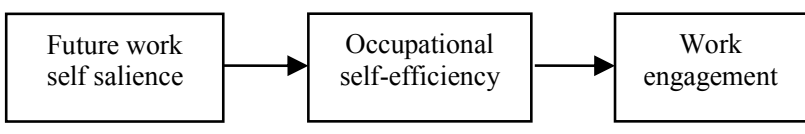

Fig. 1. Future work self salience and work engagement: The mediating role of occupational self-efficiency

\section{THEORY AND HYPOTHESES}

A Future Work Self salience refers to an individual's representation of himself or herself in the future that reflects his or her hopes and aspirations in relation to work, which represents the ease of construction and clarity of an individual's hope for work-based identity. Oyserman and Markus (1990) argued that possible selves constitute "motivational resources that individuals can use in the control and direction of their own actions [3]. They motivate self-directed behaviors aimed at change and self-development. According to the identity construction theory, Salient identities are of high subjective importance in identifying or defining the self [4]. Activated salient possible selves organize and energize individual's behavior aimed at bringing them about. Salient Future Work Selves thus create discrepancies that lead individuals to actively strive for their best possible future in line with their values rather than focusing on what others expect them to do [5] [6]. Extensive finds have yielded support for the positive relationship between future work self salience and work engagement. May et al. (2004) noted that clear self-concept was positively correlated with work engagement [7]. Hall and Chandler(2005)proposed that individual with clarity career related self-concept was more easily found calling through experiencing the meaning of work, and the calling also represents a high degree of work engagement [8]. Zhang base on a sample of 447 new generation Chinese employees showed that core self-evaluation has positively related to work engagement. Accordingly, we proposed the following hypothesis:

Hypothesis1: Future work self salience relates positively to work engagement.

Future Work Selves provide an essential link between self-concept and behavior, and function as incentives for 
future behavior in relation to work. According to self-determination theory, individuals will compare their Future Work Self with their current self to set their self-regulation goals. Future Work Selves that are salient motivate anticipatory and future-oriented behavior and enable people to work towards an imagined future. They identify discrepancies that form the basis of self-directed behavior to bring about their desired future.

First, future work self salience will promote occupational self-efficiency. For salient future work selves support the process through which self-set goals are defined and help to generate strategies to strive toward these goals. A higher level of future work self salience will lead more efficiency of occupation goals. So a salient Future Work Self generates a motivating discrepancy and invokes occupation self-efficiency. Guan (2013) suggests that a salient future work self motivates individuals to develop a higher level of career adaptability, which then enhance their job search self-efficacy [9].

Second, we argue that occupation self-efficiency will promote work engagement. Occupational self-efficiency refers to the competence that a person feels concerning the ability to successfully fulfill the tasks involved in his or her job [10]. Self-efficacy can be seen as a personal resource, acting as a buffer in the stressor-strain relationship. According to Hackett and Betz (1981), personal efficacy had strong relationship to many career related behaviors, and while it has it also has direct relevance to the understanding and modification of career related behaviors [11]. It is reasonable to argue that occupational self-efficiency will affect the individual's efforts in the professional perseverance, which means the higher occupational self-efficiency will advance personal work engagement via facilitating their work role. Otherwise, the alienation of work role due to low occupational self-efficiency will bring down the work engagement. Number of studies witnessed the impact of self-efficiency on work engagement. For instance, Christian (2007) and Li (2015) showed that Self-efficacy was positively related to each dimension of work engagement [12-13]. Occupational self-efficacy can help individuals effectively cope with job burnout [14]. Accordingly, we argue that future work self salience will promote work engagement through individual's occupational self-efficacy. In other words, occupational self-efficiency mediates relationship

Hypothesis2: Future work self salience relates positively to occupational self-efficiency.

Hypothesis3: Occupational self-efficiency mediates the relationship between future work self salience and work engagement.

\section{METHOD}

\section{A. Participants and procedures}

We collected data from 572 new generation employees (born after 1980) of 57 companies in china. Data were collected in form of on-line survey and field survey. Participation was voluntary, and all participants were assured of anonymity of their responses.572 participants completed the questionnaires, for a response rate of $83 \%$. Their demographic data were as follows: $53.8 \%$ of the employees $(n=475)$ were male; $71.4 \%$ had college degrees and the rate of general staff was $85.7 \%$.

\section{B. Measures}

\section{1) Future work self salience}

Future work self salience was rated by a 5 -item developed by Strauss et al. (2012) which modified form the measure of salience of possible selves [2]. Participants were asked to rate their agreement on a 5-point scale (1=strongly disagree, $5=$ strongly agree). A sample items is I am very clear about who and what I want to become in my future. Cronbach's $\alpha$ was 0.76 .

\section{2) Work engagement}

Work engagement was measured by Schaufeli and Salanova (2001) 9-item UWES scale [15]. The Utrecht Work Engagement Scale (UWES) includes the three constituting dimensions of work engagement: vigor, dedication, and absorption. Participants were asked to rate their agreement on a 5-point scale (1=strongly disagree, 5=strongly agree). Sample items include "At my work, I feel bursting with energy, when I get up in the morning, I feel like going to work". Cronbach's $\alpha$ was 0.78 .

\section{3) Occupational self-efficiency}

Occupational self-efficiency was measured by Rigotti, Schyns and Mohr (2008) 9-item scale [16]. Participants were asked to rate their agreement on a 5 -point scale $(1=$ strongly disagree, $5=$ strongly agree). For global indicator, Cronbach's $\alpha$ was between 0.85 and 0.9 .

\section{4) Control variables}

Participants' demographic, including gender and education level was measured as control variables, because they may affect variables in research.

\section{RESULT}

\section{A. Descriptive statistics and correlations}

To provide evidence for subsequent hypothesis test, we applied the correlation analysis. The descriptive and correlations between future work self salience, occupational self-efficiency and work engagement appear in Table I . Results showed that FWSS related positively to WE $(\mathrm{r}=0.217$, $\mathrm{P}<0.01)$ and $\mathrm{OSE}(\mathrm{r}=0.326, \mathrm{P}<0.01)$.

TABLE I. CORRELATION ANALYSIS

\begin{tabular}{|l|c|c|l|l|l|}
\hline \multirow{2}{*}{$\begin{array}{c}\text { Correlation } \\
\text { Analysis }\end{array}$} & \multicolumn{5}{|c|}{ Descriptive Statistics and Correlations } \\
\cline { 2 - 6 } & $\boldsymbol{M}$ & $\boldsymbol{S D}$ & $\boldsymbol{1}$ & $\mathbf{2}$ & $\mathbf{3}$ \\
\hline $1 . \mathrm{FWSS}$ & 3.48 & 0.624 & 1 & & \\
\hline $2 \mathrm{WE}$ & 3.47 & 0.838 & $0.217^{* *}$ & 1 & \\
\hline $3 . \mathrm{OSE}$ & 3.40 & 0.532 & $0.326^{* *}$ & $0.625^{* *}$ & 1 \\
\hline
\end{tabular}

Notes. FWSS=future work self salience. WE=work engagement. OSE=occupational self-efficiency.

\section{B. Hypothesis test}

We use SEM (Structural Equation Model) to examine the relationship between future work self salience and work engagement via occupational self-efficiency. The path coefficient of future work self salience on work engagement was $0.52(\mathrm{p}<0.001)$. According to goodness-of-fit indices, 
$\chi 2 / \mathrm{df}=2.622, \mathrm{GFI}=0.947, \mathrm{AGFI}=0.921, \mathrm{NFI}=0.950, \mathrm{CFI}=0.96$, $\mathrm{IFI}=0.968$, TLI $=0.959$, RMSEA $=0.060$. This result showed that future work self salience relates positively to work engagement. Therefore, Hypothesis 1 was supported.

We use causal steps approach to test mediation model. The test procedure as follows: first, we had examined the significant direct effect of future work self salience on work engagement. Second, we use SEM (Structural Equation Model) to examine the relationship between future work self salience and occupational self-efficiency. As shown in Fig.2, the path coefficient of future work self salience on occupational self-efficiency was $0.67(\mathrm{p}<0.001)$. According to goodness-offit indices, $\chi 2 / \mathrm{df}=1.867, \mathrm{GFI}=0.930, \mathrm{AGFI}=0.9, \mathrm{NFI}=0.939$, CFI $=0.959, \quad$ IFI $=0.960, \quad$ TLI $=0.949, \quad$ RMSEA $=0.064$. This result showed that future work self salience relates positively to occupational self-efficiency. Third, we examined the mediating effect of occupational self-efficiency, the result of mediation analysis showed that the path coefficient of occupational self-efficiency on work engagement was 0.61 $(\mathrm{p}<0.001)$ and the path coefficient of future work self salience on work engagement was $0.35(\mathrm{p}<0.01)$, According to goodness-of-fit indices, $\chi 2 / \mathrm{df}=1.792, \quad \mathrm{GFI}=0.909$, AGFI $=0.879, \mathrm{NFI}=0.933, \mathrm{IFI}=0.956, \mathrm{TLI}=0.947, \mathrm{CFI}=0.956$, RMSEA $=0.064$. The Fig.2 showed that occupational self-efficiency had a significant mediating effect on the future work self salience and work engagement. Thus, Hypothesis 2 and Hypothesis 3 were supported.

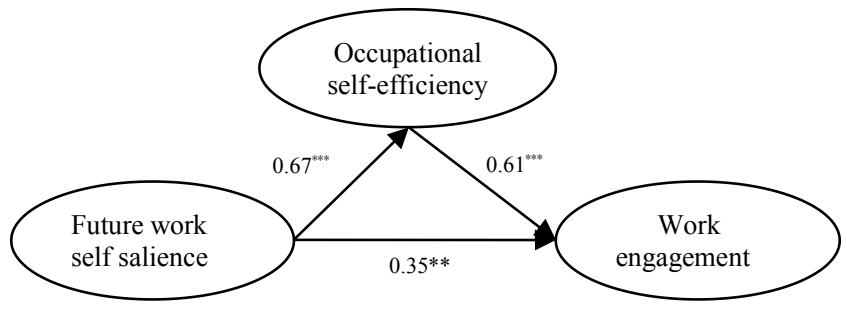

Fig. 2. Mediation model test result

\section{CONCLUSION}

In summary, the current study flourishes the work engagement by examining the relationship between future work self salience and work engagement. The findings revealed that occupational self-efficiency mediated the relationship between future work self salience and work engagement. This line of investigation would advance current understanding on how self concept shape individual's work engagement.

The findings of the current study offer several practical implications. First, Future Work Selves provide an essential link between self-concept and behavior, and function as incentives for future behavior in relation to work. Organizations should consider to develop the future work self of new generation employees. Companies could provide training program to help new generation employees to set up their future career goals. Second, skill training program and work experience sharing training program could provide to advance occupation self-efficiency of new generation employees. Third, job rotation and career mentor are needed for new generation employees. These human resource management practices would help them to advance the fitness of vocation.

\section{LIMITATIONS AND FUTURE RESEARCH}

This study has several limitations. First, the source of our data was limited, which might be subjected to common method variance. Meanwhile, all measure scales were using self-report method which might be caused social desirability deviance. We call future research to use longitudinal design to rigorously test the causal relationships between future work self salience and work engagement. Second, work engagement was generally affected by lots of situational factors. Specially, Chinese traditional culture factor would play as an important moderate factor in the model. Therefore, examining the effect of traditional culture factors will be a fruitful path for future research.

\section{ACKNOWLEDGEMENT}

This research was financially supported by the Ministry of education of Humanities and Social Science project (13XJC630002) and the12th Five-year Educational Science Planning Project of Chongqing (2014-GX-037).

\section{REFERENCES}

[1] K. Willyerd, “The 2020 Workplace," Unabridged, Poetry.

[2] K. Strauss, M.A. Griffin, and S.K. Parker, "Future work selves: how salient hoped-for identities motivate proactive career behaviors," Journal of Applied Psychology, vol. 97, 2012, pp. 580-598.

[3] D. Oyserman, and H.R. Markus, "Possible selves and delinquency," Journal of Personality \& Social Psychology, vol. 59, 1990, pp. 112-25.

[4] R.H. Hoyle, and M.R. Sherrill, "Future Orientation in the Self - System: Possible Selves, Self - Regulation, and Behavior," Journal of Personality, vol. 74, 2006, pp. 1673-1696.

[5] B.E. Ashforth, and F. Mael, "Social Identity Theory and the Organization," Academy of Management Review, vol. 14, 1989, pp. 20-39.

[6] A. Leondari, Syngollitou, and G. Kiosseoglou, "Academic Achievement, Motivation and Future Selves," International Journal of Adolescence \& Youth, vol. 24, 1998, pp. 165-177.

[7] D.R. May, R.L. Gilson, and L. M, Harter, "Psychological conditions of meaningfulness, safety and availability and the engagement of the human spirit at work," Journal of Occupational \& Organizational Psychology, vol. 77, 2004, pp. 11-37.

[8] T. Hall, Douglas, and D.E. Chler, "Psychological success: When the career is a calling," Journal of Organizational Behavior, vol. 26, 2005, pp. 155-176.

[9] Y. Guan, "New job market entrants' future work self, career adaptability and job search outcomes: Examining mediating and moderating models," Journal of Vocational Behavior, vol. 85, 2014, pp. 136-145.

[10] R.M.G Gumbau, M.S. Soria, and J.M.P. Silla, "Moderator effects of self-efficacy on occupational stress," Psychology in Spain, 2001, pp. 63-74.

[11] G. Hackett, and N.E. Betz, "Self-efficacy approach to the career development of women," Journal of Vocational Behavior, vol. 18, 1981, pp. 326-339.

[12] M.S. Christian, and J.E. Slaughter, "Work engagement: A meta-analytic review and directions for research in an emerging area," Academy of Management Annual Meeting Proceedings, 2007.

[13] W. Mischel, and Y. Shoda, "Reconciling processing dynamics and personality dispositions," Annual Review of Psychology, vol. 49, 1998, pp. 229-58. 
[14] W.B. Swann, A. Stein-Seroussi, and R.B. Giesler, "Why people self-verify," Journal of Personality \& Social Psychology, vol. 62, 1992, pp. 392-401.
[15] P. Seppälä, "The Construct Validity of the Utrecht Work Engagement Scale: Multi sample and Longitudinal Evidence," Journal of Happiness Studies, vol. 10, 2009, pp. 459-481.

[16] M. Tranberg, S. Slane, and S.E. Ekeberg, "The Relation between Interest Congruence and Satisfaction: A Meta analysis," Journal of Vocational Behavior, vol. 42, 1993, pp. 253-264. 